\title{
Simulation of Drilling Pressure Profile in Directional Drilling and User Program Development
}

\author{
Weerapong Panichaporn, Ruktai Prurapark, and Kitipat Siemanond
}

\begin{abstract}
Maintaining wellbore stability is challenging in any drilling situation, especially when directional drilling with narrow pressure window are experienced. An imperative parameter to control wellbore stability is downhole pressure or equivalent circulating density (ECD). An accurate downhole pressure is required in order to maintain it in pressure window and also avoid drilling problems which cause interruption during drilling operation, resulting in high non-productive time. Since annular frictional pressure loss increases ECD, it becomes very challenging to estimate accurate annular pressure loss. Many experimental studies have been developed annular pressure loss prediction without validating results with field measurements. This study aims to estimate an annular pressure loss in directional drilling with or without pipe rotation using several developed models with casing program. The performance of the models are tested by comparing the results with field measurements obtained from Kam Phaeng San Basin, Thailand. The conventional annular frictional pressure loss combined with increasing-pressure-loss model gives a good agreement with field measurements, a pipe rotation effect is more influential on annular pressure loss especially in smaller annular space. In addition, a user-friendly software is also developed using MATLAB platform to predict real time downhole pressure and ECD with casing program.
\end{abstract}

Index Terms-Downhole pressure, annular pressure loss, equivalent circulating density (ECD), directional drilling.

\section{INTRODUCTION}

Keeping the downhole pressure or drilling fluid equivalent circulating density (ECD) in the operating window between the pore and the fracture pressure is very challenging, particularly when the pressure window is very narrow. When downhole pressure is above fracture pressure, drilling fluid leaks into the formation, and it causes formation damages. On the other hand when downhole pressure is below pore pressure, formation fluid will influx into wellbore leading to kick and blowout. Both situations can cause fluid circulation loss. Thus, to overcome these challenges, an accurate estimation of pressure loss is essential to avoid drilling problem, resulting in an increase of non-productive time. This downhole pressure consists of hydrostatic pressure from fluid exerted in wellbore and frictional annular pressure from fluid flow. To predict an accurate frictional pressure loss, fluid flow behavior in annular space of wellbore should be determined. Many published literatures have been studied the fluid rheology, flow state, and also effect of parameters such

Manuscript received February 15, 2015; revised April 30, 2015.

Weerapong Panichaporn and Kitipat Siemanond are with the Petroleum and Petrochemical College, Chulalongkorn University, Thailand (e-mail: n_weera@hotmail.com, kitipat.s@chula.ac.th).

Ruktai Prurapark is with the Energy Thai Trading Hub Company Limited (ETTH), Thailand (e-mail: ruktai.p@etth.co.th). as pipe rotation, fluid properties and flow rate that affect frictional annular pressure loss calculation. However proposed predictive models has never been validated with field measurements, and never been applied to practical fields.

In this research, several developed models have been conducted to estimate downhole pressure while circulating power law fluid in concentric annulus, and validate the results with field measurements obtained from Kam Phaeng San Basin, Thailand. In addition, the effect of drillpipe rotation on annular pressure loss is also studied. The optimum predictive model which is analyzed by using statistical method is used in development of friendly-user software using MATLAB platform.

\section{FIELD MEASUREMENTS}

Field measurements used in this study are obtained from Kam Phaeng San Basin, Thailand by incorporating with Pan Orient Energy (Siam) Company Limited. The four different onshore wells that used in this research; A, B, C and D are directional drilling at target true vertical depth $935 \mathrm{~m}, 796 \mathrm{~m}$, $1,253 \mathrm{~m}, 1,408 \mathrm{~m}$ respectively, and measured depth 1,660 m, $890 \mathrm{~m}, 1,651 \mathrm{~m}, 1,552 \mathrm{~m}$ respectively. Wells are drilled in hole section 26 inch, $171 / 2$ inch, $121 / 4$ inch, $81 / 2$ inch and $6 \frac{1}{8}$ inch with casing size 20 inch, $13 \frac{3}{8}$ inch, $9 \frac{5}{8}$ inch, 7 inch and $4 \frac{1}{2}$ inch respectively and with drillpipe 5 inch following well program. Drilling fluid flow are approximately in range 350750 gallon per minute. Downhole pressure or equivalent circulating density (ECD) in field were measured by rig sensor, which were recorded in Log ASCII Standard format.

\section{MAthematicAl MODELS}

Downhole pressure are generated from two different origin: hydrostatic pressure and frictional losses. The hydrostatic pressure exerted by the column of fluid inside wellbore while frictional losses are generated by fluid flowing in annulus from bottom of hole to surface. In field operation, this downhole pressure is usually referred to equivalent circulating density (ECD) which is the effective density exerted by a circulating fluid against formation, expressing in pound per gallon (ppg). Thus, downhole pressure and ECD can be expressed in (1) and (2) respectively [1], [2].

$$
\begin{gathered}
B H P=\Delta P_{\text {hydrostatic }}+\Delta P_{\text {annular }} \\
E C D=E M W+\frac{\Delta P_{\text {annular }}}{0.052 \times T V D}
\end{gathered}
$$

To achieve an accuracy of downhole pressure or ECD, an 
annular pressure loss calculation is determined using a narrow slot equation for pipe flow because it is widely used in the drilling engineering for practical purposes. To transform annular flow to pipe flow, the effective diameter needs to be replaced the diameter parameter. Anifowoshe $e t$ al. [3] found that the definition of hydraulic diameter as expressed in (3) is the appropriate estimation of pressure loss for power law fluid. Hence frictional pressure loss inside an annulus using slot equation is defined as (4)

$$
\begin{aligned}
& D_{e}=D_{o}-D_{i} \\
& \frac{d P}{d z}=\frac{f_{f} \rho v_{a}^{2}}{25.81\left(D_{o}-D_{i}\right)}
\end{aligned}
$$

where $D_{0}$ and $D_{i}$ are wellbore diameter or casing diameter and drillpipe diameter respectively, $\rho$ is static density, $v_{a}$ is average annular velocity and $f_{f}$ is friction factor.

\section{A. No Effect of Pipe Rotation}

A friction factor significantly depends on fluid flow state either in laminar regimes, transition regimes or turbulent regimes, thus flow state should be determined in order to predeict the pressure losses. The flow in annulus is either laminar flow, transitional flow or turbulent flow depending on the parameters such as flow rate, density, and diameter ratio. The flow state is classified dimensionless Reynold number which is less than 2100 for laminar flow and more than 4000 for turbulent flow. A common friction factor in laminar regime can be describe in (5), and for turbulent regime in (6). A friciton factor of transition regime is calculated using linear regression between larminar and turbulent regime. However, a friction factor for power law fluid, Blasius formula, in turbulent regime is also proposed as (7).

$$
\begin{gathered}
f_{f}=\frac{16}{N_{R e}} \\
f_{f}=\frac{4}{n^{0.75}} \log \left(N_{R e} f_{f}^{1-\frac{1}{n}}\right)-\frac{0.395}{n^{1.2}} \\
f_{f}=\frac{0.0791}{N_{R e} e^{0.25}}
\end{gathered}
$$

\section{B. Effect of Pipe Rotation}

Inside annulus, inner pipe rotation can help increasing penetration rate to drill in deeper depth and also transporting cuttings up to the surface to reduce pipe stuck and pressure build up from an accumulation of cuttings in annular gap. However pipe rotation generates a tangential flow in the same direction as rotation, which resists the flow in axial direction leading to an increase of annular pressure loss. Moreover a rotating pipe also generates a secondary turbulent flow (vortex) inside main turbulent stream. It not only creates more turbulent regime but also resists the fluid flow affecting an increase of annular pressure loss. Although, a study of flow behavior when pipe is rotating is still complex especially in drilling operation, there are several literatures proposed empirical correlations and mechanistic models. Hemphill et al. [4] developed the general equation for increased pressure loss with rotation in term of diameter ratio and rotation speed (rpm) as expressed in (8)

$$
\Delta P_{\text {rotate }}=-1.0792\left(\frac{D_{i}}{D_{o}}\right)+17.982\left(\frac{D_{i}}{D_{o}}\right)^{2}(0.00001 \times L \times N)
$$

where $L$ is length section and $\mathrm{N}$ is rotation speed. Ozbayoglu et al. [5] proposed the empirical correlation for friction factor in term of both axial and tangential Reynolds number. Friction factor can be classified using total Reynold number, which is the sum of axial and tangential Reynold number, as given below

$$
\begin{aligned}
& \text { If } N_{R e_{T}}<3000 \\
& \qquad \begin{aligned}
f_{f} & =8.274 N_{R e_{a}}-0.9075+0.00003 N_{R e_{r}} \\
\text { If } 3000 & <N_{R e_{T}}<7000 \\
f_{f} & =0.0729 N_{R e_{a}}{ }^{-0.3017+0.000011 N_{R e_{r}}} \\
\text { If } 7000 & <N_{R e_{T}}<10000 \\
f_{f} & =0.006764 N_{R e_{a}}{ }^{-0.0286}+0.00001 N_{R e_{r}}
\end{aligned}
\end{aligned}
$$

If $10000<N_{R e_{T}}<25000$

$$
f_{f}=8.28 N_{R e_{a}}{ }^{-0.7258}+0.000001 N_{R e_{r}}
$$

If $25000<N_{R e_{T}}<40000$

$$
f_{f}=0.06188 N_{R e_{a}}{ }^{-0.2262}
$$

If $N_{R e_{T}}>40000$

$$
f_{f}=0.03039 N_{R e_{a}}{ }^{-0.1542}
$$

where $N_{R e_{T}}$ is total Reynold number, $N_{R e_{a}}$ is axial Reynold number and $N_{R e_{r}}$ is tangential Reynold number.

Ahmed et al. [6] introduced the pressure loss ratio (PLR), which is the ratio of pressure loss while pipe rotating at that speed and pressure loss with no pipe rotation, from field measurements with dimensionless analysis expressed in (15)

$$
\begin{aligned}
& P L R=0.36 \times\left(13.5+\frac{\tau_{y}}{\rho U^{2}}\right)^{0.428} \times \varepsilon_{\text {ave }}^{0.158} \times n^{0.054} \times \\
& T a \times R e_{e f f}^{0.042} \times k\left(\frac{1}{k}-1\right)^{-0.0152}
\end{aligned}
$$

where $\tau_{y}$ is yield stress, $\varepsilon$ is eccentric value, $T a$ is Taylor number, and $R e_{\text {eff }}$ is effective Reynolds number. The default values and calculation details are followed given references.

Erge et al. [7] presented a new correlation for laminar region, transition from laminar to turbulent regions and turbulent region to propose new friction factor $\left(f_{0}\right)$ in order to predict annular pressure loss with pipe rotation. The expression are described as follow:

$$
f_{0}=(c) f_{\text {Mod .N.S. }}
$$

For laminar flow:

$$
c=0.2287 N-0.0580 F_{d}+0.1237 \omega_{d}+0.4289
$$


For transition flow:

$$
c=-1.0267 N-0.0096 F_{d}+0.0390 \omega_{d}+1.2422
$$

For turbulent flow:

$$
c=1.7821 N-0.0132 F_{d}+0.1388 \omega_{d}+1.7983
$$

where $N$ is consistency index, $F_{d}$ is the dimensionless force and $\omega_{d}$ is the dimensionless rotation.

Therefore, several published models of predicting annular pressure loss with and without drillpipe rotation are summarized as shown in Table I.

TABLE I: PREDICTIVE MODELS OF ANNULAR PRESSURE LOSS WITH AND

\begin{tabular}{|c|c|}
\hline $\begin{array}{l}\text { Model without pipe } \\
\text { rotation }\end{array}$ & Model with pipe rotation \\
\hline \multirow{2}{*}{$\begin{array}{l}(5),(6) \\
(\text { Model A) }\end{array}$} & $(5),(6),(8) \quad-->>$ Model A1 \\
\hline & (5), (6), (15) ---> Model A2 \\
\hline \multirow{4}{*}{$\begin{array}{l}(5),(7) \\
\text { (Blasius formula) }\end{array}$} & $(5),(7),(8) \quad--->$ Model B1 \\
\hline & $(5),(7),(15)$---> Model B2 \\
\hline & ---> Model C \\
\hline & ---> Model D \\
\hline
\end{tabular}
WITHOUT DRILLPIPE ROTATION

\section{RESULTS AND DISCUSSIONS}

Regarding the drilling fluid parameters: Plastic viscosity $(P V)$ and yield point $(Y P)$ obtained from field measurement, drilling fluid behavior in annular gap is described as power law fluid flow. Thus, fluid behavior index $(n)$ and consistency index $(k)$ of four different wells in hole section of $8 \frac{1}{2}$ inch diameter are determined and shown in Table II.

In field operation, well is drilled with different bit and casing program that provide different annular geometry in each section. When fluid flows passing through this gap, mean velocity is changed which affect the determination of flow state whether in laminar or turbulent region. Using drilling fluid parameters combined with bit and casing program from actual well program, predicting pressure loss models with and without pipe rotation are summarized in Table I in order to predict ECD or downhole pressure.

\section{A. Downhole Pressure without Pipe Rotation}

An annular frictional pressure loss calculation without pipe rotation effect is conducted using Model A and Blasius formula as shown in Table I combining bit and casing program. Then annular pressure loss are added with hydrostatic pressure, and express downhole pressure in term of ECD. The comparison of calculated and measured ECD without pipe rotation effect based on field measurement of well A is shown in Fig. 1.

Fig. 1 indicates that the Blasius model gives a good agreement with field measurements more than Model A. The Blasius formula was developed using only power law fluid information while Model A is commonly used for both Newtonian fluid and Non-Newtonian fluid. Nonetheless, error lines indicate that both models are under predicted for ECD or downhole pressure estimation. Additionally, usual measured ECD are in range 9-13 ppg, but there are some abnormal data which is over the normal range because of oilfield data transformation. Regarding to oilfield data record, all drilling information are recorded as time log including data not only in drilling activities but also others such as hole cleaning, tripping in-out and pipe connection. Transforming time $\log$ to depth $\log$, which is considered only in drilling activities, might not have an appropriate algorithm of transformation. Hence, the pressure peaks at measured depth (MD) from 900 to $960 \mathrm{~m}$ are caused by unusual flow rate from hole cleaning activity. On the other hand, it indicates that flow rate is a major influence of estimating ECD and pressure loss. In addition, an error becomes more fluctuating at depth deeper than $780 \mathrm{~m}$ since it changes the bit from $12 \frac{1 / 4}{4}$ inch to $8 \frac{1}{2}$ inch bit diameter with 5 inch drillpipe diameter. The narrow annular space also influences pressure loss.

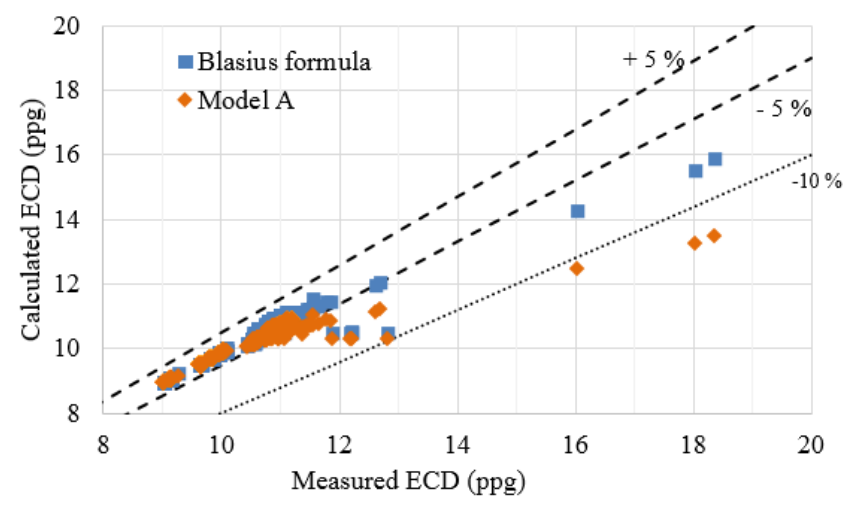

Fig. 1. A comparison of calculated ECD and measured ECD from Blasius formula and model a using well a data.

\section{B. Downhole Pressure with Pipe Rotation}

The gap width between drillpipe and wellbore or inner casing can cause pipe rotation effect becoming more dominant especially in hole section of $81 / 2$ inch diameter or narrower annular gap. Since an inner pipe rotational speed at the pipe wall effects axial velocity and it impacts overall shear rate that controls pressure loss, the effect of drillpipe rotation on pressure loss is considered to evaluate ECD or downhole pressure using models in Table I.

Predictive models of annular frictional pressure loss with pipe rotation are conducted to calculate ECD or downhole pressure based on Well A while circulating power law fluid in hole section of $81 / 2$ inch diameter. The comparison between calculated ECD and measured ECD from Model A1 and A2, Model B1 and B2, and Model C and D are shown in Fig. 2-Fig. 4 respectively.

TABLE II: AN EXAMPLE OF FLUID PROPERTIES IN HOLE SECTION OF 81/2 INCH IN DIAMETER

\begin{tabular}{cccccc}
\hline \hline Mud Properties & Unit & Well A & Well B & Well C & Well D \\
\hline Plastic viscosity (PV) & cps & 13 & 13.5 & 14.5 & 11 \\
Yield Point (YP) & $1 b / 100 f t^{2}$ & 17.5 & 17 & 16.5 & 18.5 \\
Flow behavior index (n) & - & 0.5122 & 0.5287 & 0.5536 & 0.4572 \\
Consistency index $(\mathrm{k})$ & eq.cp & 638.32 & 575.96 & 501.22 & 869.91 \\
Yield stress $\left(\tau_{\mathrm{y}}\right)$ & $1 b / 100 f t^{2}$ & 0 & 0 & 0 & 0 \\
\hline \hline
\end{tabular}

Fig. 2 and Fig. 3 indicate that Model A1 and B1 using increase-pressure-loss model give a good agreement with with field measurement with slightly under prediction. While Model A2 and B2 using pressure loss ratio (PLR) give 
slightly over prediction. An increase-pressure-loss model is more accurate than pressure loss ratio model because an increase-pressure-loss model was developed from several field measurement based on different well geometry or diameter ratio between drillpipe and wellbore diameter. While PLR was also developed from field measurement based on drilling fluid properties which PLR can be used either in power law fluid or yield power law fluid. On the other hand, annular gap width or diameter ratio between drillpipe and wellbore significantly impact on ECD or downhole pressure while drillipipe is rotating.

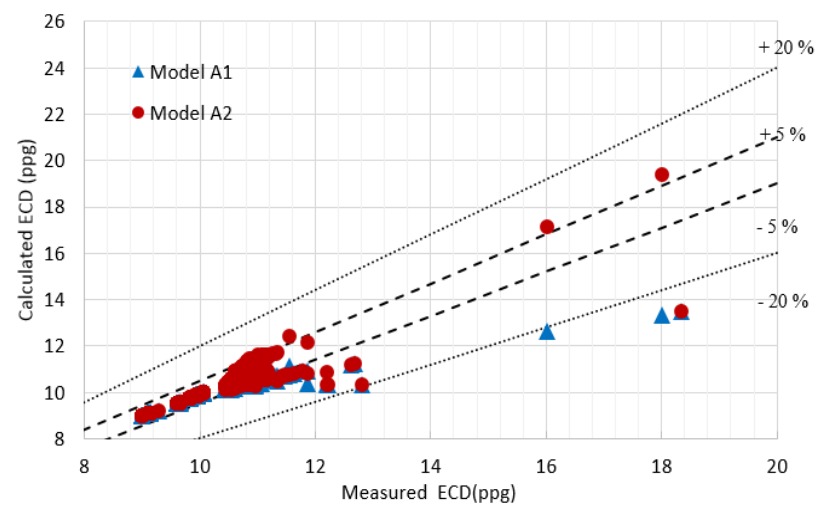

Fig. 2. A comparison of calculated ECD and measured ECD from model A1 and model A2 using well a data.

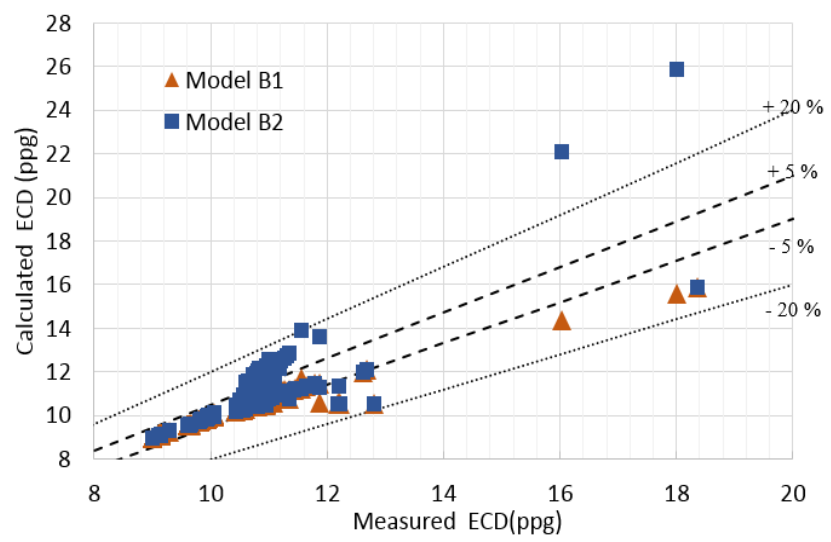

Fig. 3. A comparison of calculated ECD and measured ECD from model B1 and model B2 using well a data.

A comparison between calculated ECD and measured ECD from model C and D are shown in Fig. 4. It is obviously that Model C slightly over predicts ECD while Model D is more acceptable. Both empirical correlation of Model C and $\mathrm{D}$ are developed using experimental data which might not represent. Abnormal ECD data are occured by an error of oilfield data transformation.

However, to identify an appropriate model used in developed user-friendly software, the results from four different wells are analyzed by two statistical methods; mean average relative error deviation (MARD) and root mean square error (RMSE) as shown in Table III. A deviation of predicted data are compared with measured data in every recorded depth. The less statistical value of deviation gives more accurate result, so it is obvious that the combination of Blasius formula and increased-pressure-loss equation proposed by Hemphill et al. (2008) (Model B1) can accurately estimate downhole pressure in practical field in both stationary situation and rotating drillpipe. On the other hand, decreasing annular gap width will increase pressure loss. Even though downhole pressure with the pipe rotation is presented, but if rotation effect is neglected, it causes frictional pressure loss under predicted.

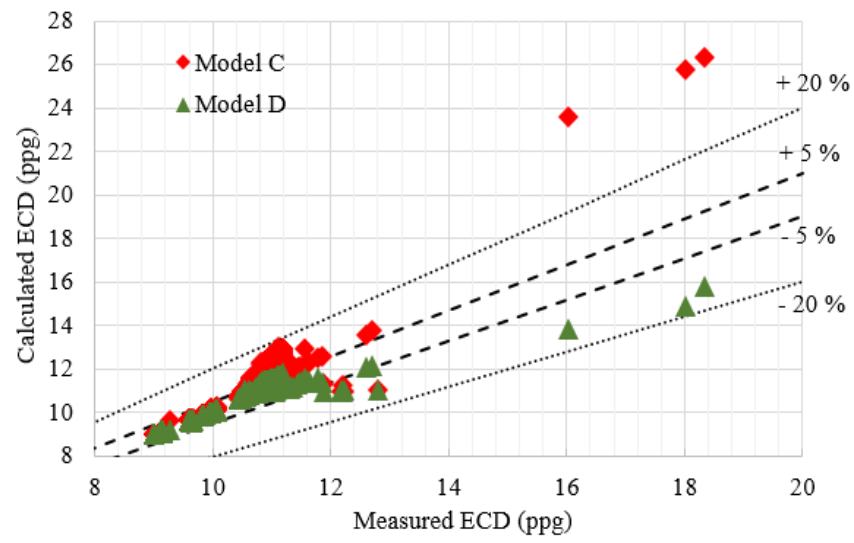

Fig. 4. A comparison of calculated ECD and measured ECD from model C and model $\mathrm{D}$ using well a data.

\section{A USER-FRIENDLY SOFTWARE DEVELOPMENT}

A user-friendly software is developed using graphic user interface (GUI) in MATLAB platform to estimate real-time ECD only in drilling activity. Typically oilfield data is recorded in Logging ASCII Standard file, and need file transformation and data arrangement to be used in pressure calculation and also displayed in GUI. A flowchart of user-friendly software is shown in Fig. 5, and a developed interface software is shown in Fig. 6.

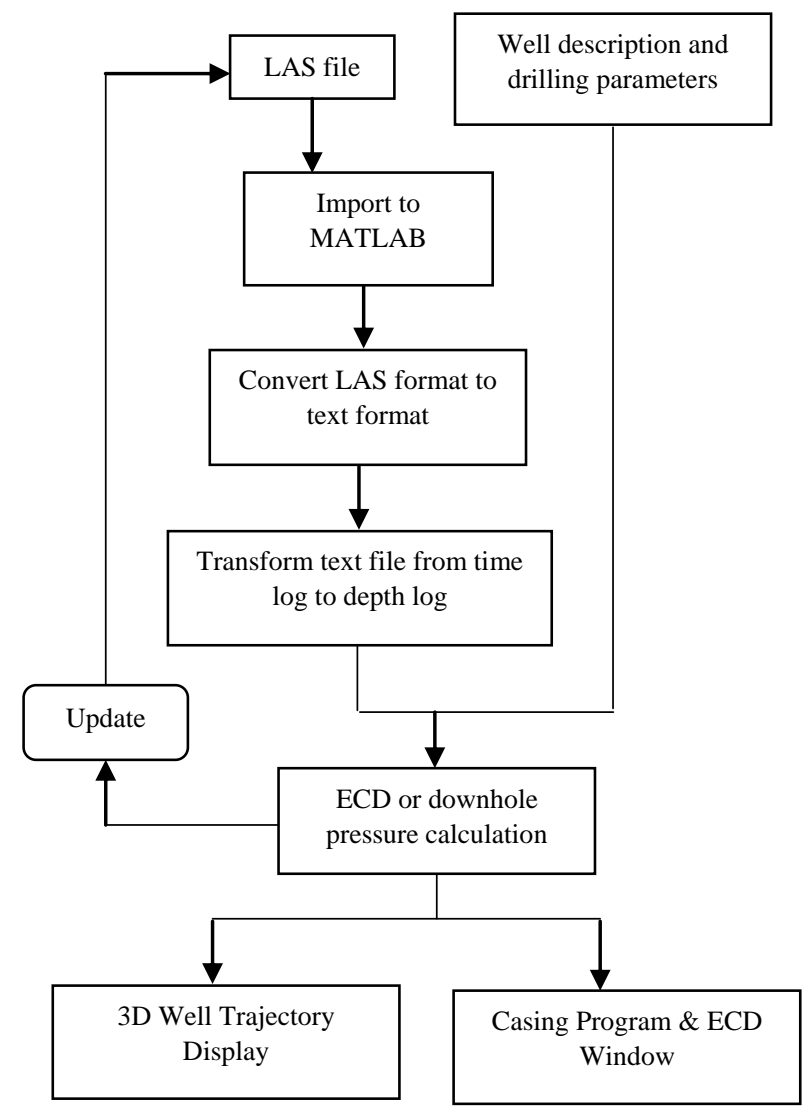

Fig. 5. A flowchart of user-friendly software. 


\begin{tabular}{|c|c|c|c|c|c|c|c|c|c|}
\hline & & \multicolumn{2}{|c|}{ Well A } & \multicolumn{2}{|c|}{ Well B } & \multicolumn{2}{|c|}{ Well C } & \multicolumn{2}{|c|}{ Well D } \\
\hline & & MARD & RMSE & MARD & RMSE & MARD & RMSE & MARD & RMSE \\
\hline \multirow{2}{*}{$\begin{array}{l}\text { Without pipe } \\
\text { rotation }\end{array}$} & Model A & 0.0203 & 0.0730 & 0.0143 & 0.0253 & 0.0128 & 0.0191 & 0.0150 & 0.0240 \\
\hline & Blasius formula & 0.0085 & 0.0151 & 0.0080 & 0.0074 & 0.0067 & 0.0049 & 0.0057 & 0.0043 \\
\hline \multirow{6}{*}{$\begin{array}{l}\text { With pipe } \\
\text { rotation }\end{array}$} & Model A1 & 0.0158 & 0.0512 & 0.0132 & 0.0220 & 0.0113 & 0.0156 & 0.0195 & 0.0127 \\
\hline & Model A2 & 0.0212 & 0.0817 & 0.0123 & 0.0198 & 0.0133 & 0.0240 & 0.0203 & 0.0639 \\
\hline & Model B1 & 0.0079 & 0.0137 & 0.0050 & 0.0035 & 0.0039 & 0.0021 & 0.0070 & 0.0087 \\
\hline & Model B2 & 0.0422 & 0.4297 & 0.0157 & 0.0518 & 0.0119 & 0.0456 & 0.0410 & 0.3599 \\
\hline & Model C & 0.0664 & 1.0839 & 0.0242 & 0.1067 & 0.0325 & 0.1891 & 0.0631 & 0.0120 \\
\hline & Model D & 0.0206 & 0.0979 & 0.0128 & 0.0341 & 0.0113 & 0.0258 & 0.0120 & 0.0312 \\
\hline
\end{tabular}

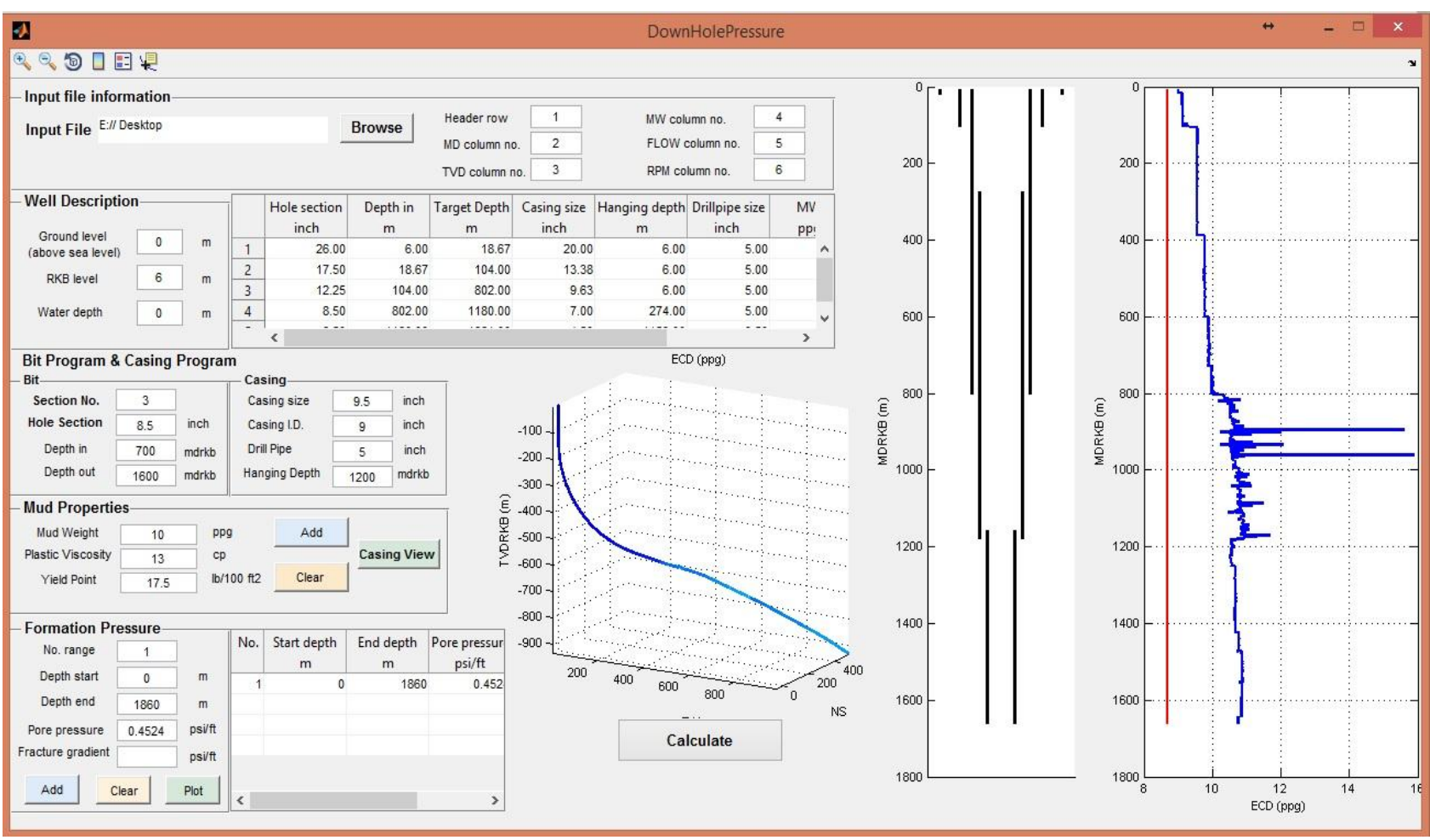

Fig. 6. A user-friendly software interface with field measurements from Well A.

\section{A. File and Information Input Section}

Most of all oilfield data are recorded in LAS file as in time log or depth log depending on rig company. When raw LAS file is in depth log, it is comfortable for software to process data and send to calculation section. On the contrary, raw LAS file recorded in time log needs some data transformation from time $\log$ to depth $\log$. This software is provided an algorithm of data transformation based on drilling parameters which are bit depth, fluid flow rate, surface weight on bit (SWOB) and drillpipe velocity to ensure that the output of depth $\log$ is considered only in drilling activity excluding hole cleaning, pipe tripping in-out and others.

In addition, well description, bit and casing program, drilling fluid properties and formation pressure are also required to manually input in software interface.

\section{B. Calculation Section}

Drilling parameters in LAS file whether in depth log or time $\log$ are accessed by MATLAB algorithm in order to rearrange necessary data into depth log. An appropriate model of calculating pressure loss analyzed by statistical method is conducted to integrate with drilling parameters and input information from user to estimate real-time ECD or downhole pressure in format of depth $\log$.

\section{Display Section}

A user-friendly program can displayed well trajectory where the position of well has been drilled, casing program with measured depth, also pressure window between ECD in pound per gallon unit and measured depth in meter unit. This displayed ECD window, widely used in oil and gas industry, is plotted comparing with pore pressure. Pore pressure, which is determined from repeat formation tester (RFT), is the pressure contains fluid inside pore volume of formation. Hence, estimated real-time ECD should be kept above pore pressure. Whenever ECD or downhole pressure is out of range from this window, for example below pore pressure, user or driller will be warned that drilling condition is harmful, and possibly lost well control. 


\section{CONCLUSION}

The downhole pressure or ECD calculation while circulating power law fluid has been studied with and without pipe rotation effect. Several published models from both empirical correlation and mechanistic models are used with practical field to accurately predict downhole pressure. A statistical analysis indicate that conventional model combined with increased-pressure-loss from rotation speed and diameter ratio gives precisely estimating pressure loss. The rotation effect becomes more dominant when annular space is narrower. An optimized model is used in a user-friendly software development. The software need the data input from LAS file and user, then it can display well trajectory, casing program and ECD window in depth log. In addition, user will be warned if drilling condition is out of pressure window.

\section{ACKNOWLEDGMENT}

The authors would like to gratefully thank to Pan Orient Energy (Siam) Company Limited (POES), The Petroleum and Petrochemical College, Chulalongkorn University and Energy Thai Trading Hubs Company Limited.

\section{REFERENCES}

[1] B. Hughes, Drilling Engineering Workbook: A Distributed Learning Course, INTEQ Training \& Development, Houston, 1995.

[2] L. W. Lake, Petroleum Engineering Handbook, Drilling Engineering, Society of Petroleum Engineers, vol. II, 2006

[3] O. Anifowoshe and S. O. Osisanya, "The effect of equivalent diameter definitions on frictional pressure loss estimation in an annulus with pipe rotation," presented at the SPE Deepwater and Completions Conference and Exhibition, Galveston, Texas, June 20-21, 2012.

[4] T. Hemphill, K. Ravi, P. Bern, and J. C. Rojas, "A simplified method for prediction of ECD increase with drillpipe rotation," presented at the 2008 SPE Annual Technical Conference and Exhibition, Denver, Colorado, USA, September 21-24, 2008.
[5] M. E. Ozbayoglu and M. Sorgun, "Frictional pressure loss estimation of non-Newtonian fluids in realistic annulus with pipe rotation," presented at the Canadian International Petroleum Conference (CIPC) 2009, Calgary, Alberta, Canada, June 16-18, 2009.

[6] R. Ahmed, M. Enfis, and H. M. E. Kheir, "The effect of drillstring rotation on equivalent circulation density: Modeling and analysis of field measurements," presented at the SPE Annual Technical Conference and Exhibition Florence, Italy, September 19-22, 2010.

[7] O. Erge, E. M. Ozbayoglu, S. Z. Miska, M. Yu, N. Takach, A. Saasen, and R. May, "The effects of drilling eccentricity, rotation and buckling configurations on annular frictional pressure losses while circulating yield power law fluids," presented at the 2014 IADC/SPE Drilling Conference and Exhibition. Fort Worth, Texas, USA, March 4-6, 2014.

Weerapong Panichaporn was born in Bangkok, Thailand in 1990. He had earned a bachelor's in chemical engineering from Mahidol University. In 2013 he got full scholarship and earned a master's in petroleum technology (international program) from the Petroleum and Petrochemical College, Chulalongkorn University, Thailand. During his master program, he worked as petroleum engineer at Energy Thai Trading Hubs Company Limited (ETTH), Thailand.

Ruktai Prurapark had earned a bachelor's in chemical engineering from Chulalongkorn University, a master's in petroleum economics, and $\mathrm{PhD}$ in petroleum engineering from Texas A\&M University. During his PhD program, he worked as lead drilling engineer for Weatherford International in Houston, Texas. During 2008 and 2010 he worked at Schlumberger in Colorado. In 2011, he was an assistance director of the Geospatial Data Center located in the Department of Civil and Environmental Engineering, Massachusetts Institute of Technology (MIT) in the US. He is currently a founder of Energy Thai Trading Hubs Company Limited (ETTH), Thailand, and also a visiting professor at the Petroleum and Petrochemical College, Chulalongkorn University, Thailand.

Kitipat Siemanond had earned a bachelor's in chemical technology from Chulalongkorn University, Thailand, a master's in chemical engineering from Texas A\&M-Kingsville University, USA. In 1997 he earned PhD in chemical engineering from Lamar University, USA. He is currently an assistant professor at the Petroleum and Petrochemical College, Chulalongkorn University, Thailand. His current research interests are process simulation and control, applications of pinch technology, and numerical methods for chemical engineering. 